\title{
BMJ Open Haematological profile of chronic kidney disease in a mixed-ancestry South African population: a cross- sectional study
}

\author{
Cindy George, ${ }^{1}$ Tandi E Matsha, ${ }^{2}$ Rajiv T Erasmus, ${ }^{3}$ Andre P Kengne ${ }^{1,4}$
}

To cite: George $C$, Matsha TE, Erasmus RT, et al. Haematological profile of chronic kidney disease in a mixed-ancestry South African population: a crosssectional study. BMJ Open 2018;8:e025694. doi:10.1136/ bmjopen-2018-025694

- Prepublication history for this paper is available online. To view these files, please visit the journal online (http://dx.doi org/10.1136/bmjopen-2018025694).

Poster presented at the 28th European Meeting on Hypertension and Cardiovascular Protection, held in Barcelona, 8-11 June 2018. As such, the results have been published as an abstract.

Received 26 July 2018 Revised 10 September 2018 Accepted 3 October 2018

Check for updates

(C) Author(s) (or their employer(s)) 2018. Re-use permitted under CC BY-NC. No commercial re-use. See rights and permissions. Published by BMJ.

For numbered affiliations see end of article.

Correspondence to

Dr Cindy George;

cindy.george@mrc.ac.za

\section{ABSTRACT}

Objectives The objectives were to characterise the haematological profile of screen-detected chronic kidney disease (CKD) participants and to correlate the complete blood count measures with the commonly advocated kidney function estimators.

Methods The current cross-sectional study used data, collected between February 2015 and November 2016, of 1564 adults of mixed-ancestry, who participated in the Cape Town Vascular and Metabolic Health study. Kidney function was estimated using the Modification of Diet in Renal Disease (MDRD) and Chronic Kidney Disease Epidemiology Collaboration (CKD-EPI) equations. CKD was defined as estimated glomerular filtration rate (eGFR) $<60 \mathrm{~mL} / \mathrm{min} / 1.73 \mathrm{~m}^{2}$, and anaemia as haemoglobin level $<13.5 \mathrm{~g} / \mathrm{dL}$ (men) and $<12 \mathrm{~g} / \mathrm{dL}$ (women).

Results Based on the MDRD and CKD-EPI equations, the crude prevalence of CKD was $6 \%$ and $3 \%$. Irrespective of the equation used, median red blood cell (RBC) indices were consistently lower in those with CKD compared with those without CKD (all $p<0.0001)$. Despite not showing any significant difference in total white blood cell (WBC) count between the two groups, the number of lymphocytes were lower $(p=0.0001$ and $p<0.0001$ for MDRD and CKD$\mathrm{EPI}$, respectively) and neutrophil count (both $p<0.0297$ ) and the ratio of lymphocytes to neutrophil (both $p<0.0001$ ) higher in the CKD group compared with those without CKD; with the remaining WBC indices similar in the two groups. The platelet count was similar in both groups. Of the screen-detected CKD participants, $45.5 \%$ (MDRD) and $57.8 \%$ (CKD-EPI) were anaemic, with the prevalence increasing with increasing severity of CKD, from $37.2 \%$ (stage 3) to $82.4 \%$ (stages 4-5). Furthermore, CKD-EPIestimated kidney function, but not MDRD, was positively associated with RBC indices.

Conclusion Though it remains unclear whether common kidney function estimators provide accurate estimates of CKD in Africans, the correlation of their estimates with deteriorating RBC profile, suggests that advocated estimators, to some extent approximate kidney function in African populations.

\section{BACKGROUND}

Chronic kidney disease (CKD) is a major global public health problem, ${ }^{1}$ estimated to affect more than $10 \%$ of the general adult

\section{Strengths and limitations of the study}

- The first study to characterise the haematological profile of individuals with reduced kidney function in a population-based setting in Africa, even more specific, individuals of mixed-ancestry.

- We studied a community with a high burden of obesity, hypertension and diabetes, reflective of the current burden in Africa.

- This study was conducted in only one geographical area which may not adequately reflect all the mixed ancestry population groups in Sub-Saharan Africa.

- Our study was based on a single serum creatinine measure to determine chronic kidney disease (CKD) and did not include estimates of albuminuria. Albuminuria, which are required for clinical and aetiological diagnosis of CKD, as this information is important particularly in the interpretation of estimated glomerular filtration rate (eGFR) greater that $60 \mathrm{~mL} /$ $\mathrm{min} / 1.73 \mathrm{~m}^{2}$ where inaccuracies of the eGFR equations are greatest.

population and up to $50 \%$ of some high-risk subpopulations, such as the elderly, ${ }^{2}$ those with non-communicable diseases (NCDs), including type 2 diabetes mellitus (T2D) and hypertension, and communicable diseases (CDs), including HIV/AIDS. ${ }^{3}{ }^{4}$ Africa is currently experiencing the double burden of NCDs and CDs which are all driving the increasing burden of CKD on the continent. ${ }^{5}$ However, the exact burden of CKD in Africa has yet to be fully elucidated, ${ }^{6-9}$ in part due to the absence of appropriate estimates for predicting reduced kidney function in individuals from African ancestry. ${ }^{9} 10$

CKD encompasses a wide range of physiological processes altered by the progressive decline in glomerular filtration rate (GFR). ${ }^{1112}$ Haematological parameters, particularly red blood cell (RBC) indices, are most commonly affected, ${ }^{13}$ giving rise to anaemia. Anaemia is the most common, consistent and severe of the various haematological abnormalities, 
and has been shown to be a very common condition in black Africans. ${ }^{14}$ Although anaemia may be found at any stage of CKD, the severity of anaemia increases with CKD progression, ${ }^{15}$ resultantly affecting nearly all patients with end-stage renal disease (CKD stage 5). ${ }^{13}$ The predominant cause of anaemia in CKD is failure of the kidneys to produce enough endogenous erythropoietin, which accompanies the fall in GFR. ${ }^{16}{ }^{17}$ Untreated, prolonged anaemia is strongly predictive of all-cause and cardiovascular mortality, as well as reduced quality of life and increased morbidity in patients with CKD. ${ }^{13}{ }^{18}$ Untreated anaemia can also accelerate the decline in renal function by causing renal haemodynamic alterations and tissue hypoxia. ${ }^{15}$ Other potentially affected haematological parameters in CKD, of which the association with CKD is not yet fully characterised, include total and differential white blood cell (WBC) counts. Persistent, low-grade inflammation is an essential part of the aetiology of CKD and has been recognised as such since the late 1990s, when it was linked to cardiovascular disease and mortality. ${ }^{19}$ Recently, the ratio of neutrophil-to-lymphocyte count $(\mathrm{N} / \mathrm{L})$ has been proposed as a novel measure of inflammation in distinct populations and has been shown to have prognostic value ${ }^{20}$; particularly for mortality risk in patients with myocardial infarction and heart failure. ${ }^{2122}$ However, studies on the relationship of $\mathrm{N} / \mathrm{L}$ ratio with reduced estimated GFR (eGFR) are limited. ${ }^{23}$ Thus, despite recent advances in the aetiology governing the development and progression of CKD, population-based data on the haematological profile of people with CKD in Africa are scanty.

We therefore aimed to characterise the haematological profile of screen-detected CKD participants in a community-based sample, and to correlate the complete blood count measures with two commonly advocated kidney function estimators of CKD in urban South Africans of mixed-ancestry.

\section{METHODS}

\section{Study setting and population}

The current study used data from the ongoing Cape Town Vascular and Metabolic Health study, an extension of the Cape Town Bellville-South study, which has been described in detail previously. ${ }^{24}$ Bellville-South, with a population of approximately 29301 , is a township formed in the late 1950s, located in the metropolitan city of Cape Town, South Africa. The population consists predominantly of individuals of mixed-ancestry (coloured) $(76 \%)$, followed by black Africans $(18.5 \%)$, with only $1.5 \%$ of the population being of Caucasian and Asian ancestry. The data collection for the current analysis took place between February 2015 and November 2016 during a community-based survey involving only mixed-ancestry South Africans.

\section{Participant involvement}

The participants were not involved in the design or recruitment process of this study. However, permission to conduct the study was obtained from relevant authorities including the city and community authorities.

\section{Questionnaires and physical examination}

All interviews and physical examinations took place at a research clinic on the campus of Cape Peninsula University of Technology, located within the study suburb. All consenting participants received a standardised interview, explained in great detail elsewhere. ${ }^{25}$ Physical examination involved blood pressure (BP) determination, measured according to the WHO guidelines, ${ }^{26}$ using a semiautomatic digital BP monitor (Omron M6 comfort-preformed cuff BP Monitor), placed on the right arm in sitting position and at rest for at least $10 \mathrm{~min}$. Three measures were taken of which the average of the lowest two was used in all analyses. Body weight (to the nearest $0.1 \mathrm{~kg}$ ) was measured with the participant in light clothing and without shoes, using an Omron body fat meter HBF-511 digital bathroom scale which was calibrated and standardised using a weight of known mass. Height (to the nearest centimetre) was measured with a stadiometer, with subjects standing on a flat surface. Body mass index (BMI) was calculated as body weight per body height squared $\left(\mathrm{kg} / \mathrm{m}^{2}\right)$. Waist circumference (WC) was measured with a non-elastic tape measure at the level of the narrowest part of the torso, as seen from the anterior view. Anthropometric measurements were performed three times and the average used for analysis.

\section{Biochemical analysis and calculations}

All biochemical analyses took place at an ISO 15189 accredited Pathology practice (Path-Care, Reference Laboratory, Cape Town, South Africa). Blood samples were collected from all participants after an overnight fast, and 2 hours after a $75 \mathrm{~g}$ oral glucose tolerance test (OGTT) following the WHO recommendations. ${ }^{27}$ Plasma glucose levels and haemoglobin A1c (HbAlc) were measured by enzymatic hexokinase method (Beckman AU, Beckman Coulter, South Africa) and high performance liquid chromatography (Biorad Variant Turbo, BioRad, South Africa), respectively. Insulin was determined by a paramagnetic particle chemiluminescence assay (Beckman DXI, Beckman Coulter, South Africa). Triglycerides (TG), total cholesterol (TC), and high-density lipoproteins (HDL-C) were analysed using the Roche Modular auto analyser and enzymatic colorimetric assays, and low-density lipoproteins (LDL-C) were calculated using the Friedewald formula. ${ }^{28}$ The homeostatic model assessment of insulin resistance (HOMA-IR) was calculated according to the formula: HOMA-IR $=$ [fasting insulin concentration $(\mathrm{mIU} / \mathrm{l}) \times$ fasting plasma glucose $(\mathrm{mmol} / \mathrm{l}) / 22.5$. Serum concentration of high sensitivity C-reactive protein (hsCRP) (Immun Diagnostik AG, Bensheim, Germany) was analysed using commercially available ELISA kits according to the manufacturer's protocols. Serum creatinine was measured by the modified Jaffe-Kinetic method (Beckman AU, Beckman Coulter, South Africa). Creatinine assays at our Partner 
pathology service are standardised to the internationally accepted reference method (isotope dilution mass spectrophotometry) since 2009 and eGFR estimators applicable to standardised creatinine values were used. Kidney function was assessed using serum creatinine-based eGFR, namely, the 4-variable Modification of Diet in Renal Disease (MDRD) equation ${ }^{29}$ and the Chronic Kidney Disease Epidemiology Collaboration (CKD-EPI) equation ${ }^{30}$. The African-American ethnicity correction factor was omitted from the eGFR calculation, as the South African Renal Society CKD guidelines promote the exclusion of the correction factor, except in the case of black Africans. Full blood counts, including total RBC, total WBC, lymphocytes count and percentage, monocyte count and percentage, neutrophil count and percentage, basophil count and percentage, eosinophil count and percentage, haemoglobin, haematocrit, mean corpuscular volume (MCV), mean corpuscular haemoglobin $(\mathrm{MCH}), \mathrm{MCH}$ concentration (MCHC), red cell distribution width (RDW) and platelets were measured on a Coulter LH 750 haematology analyser (Beckman Coulter, South Africa).

\section{Classification of renal function and comorbidities}

Staging of kidney function was based on the National Kidney Foundation Disease Outcomes Quality Initiative classification. ${ }^{31}$ An eGFR $<60 \mathrm{~mL} / \mathrm{min} / 1.73 \mathrm{~m}^{2}$ was used to define CKD (or CKD stage 3-5). Anaemia was defined using the National Kidney Foundation Kidney Disease Outcome Quality Initiative (K/DOQI) guidelines (haemoglobin level $<13.5 \mathrm{~g} / \mathrm{dL}$ for men and $<12 \mathrm{~g} /$ $\mathrm{dL}$ for women $)^{32}$ and further classified into microcytic, normocytic and macrocytic based on the MCV. Microcytic anaemia was defined as an MCV of $<80 \mathrm{fL}$, normocytic as $100-80 \mathrm{fL}$ and macrocytic as $>100 \mathrm{fL} .{ }^{33}$ Hypertension was based on either a history of diagnosed hypertension (receiving medications for hypertension) or screen-detected hypertension. The latter being classified if they had a systolic BP (SBP) $\geq 140 \mathrm{~mm} \mathrm{Hg}$ and/or diastolic BP $\geq 90 \mathrm{~mm} \mathrm{Hg} .{ }^{34}$ Diabetes status was based on a history of diagnosed diabetes or screen-detected diabetes. OGTT glucose values were used to classify the glucose tolerance status of participants as recommended by $\mathrm{WHO}^{35}$ as: (1) normal glucose tolerance (fasting plasma glucose (FPG) $<6.1 \mathrm{mmol} / \mathrm{L}$ and 2-hour glucose $<7.8 \mathrm{mmol} / \mathrm{L}$ ); (2) pre-diabetes including impaired fasting glycaemia (IFG, $6.1 \leq \mathrm{FPG}<7.0 \mathrm{mmol} / \mathrm{L}$ ), impaired glucose tolerance (IGT, 7.8<2-hour glucose $<11.1 \mathrm{mmol} / \mathrm{L}$ ) and the combination of both; and (3) diabetes (FPG $\geq 7.0 \mathrm{mmol} / \mathrm{L}$ and/ or 2-hour glucose $\geq 11.1 \mathrm{mmol} / \mathrm{L}$ ). BMI $\geq 25 \mathrm{~kg} / \mathrm{m}^{2}$ and BMI $\geq 30 \mathrm{~kg} / \mathrm{m}^{2}$ were classified as overweight and obese, respectively.

\section{Statistical analysis}

All statistical analyses were performed using STATA V.13 (Statcorp), and statistical significance was based on a $\mathrm{p}$ value $<0.05$. General characteristics of the participants are summarised as count and percentage for qualitative variables and median and 25th-75th percentiles for quantitative variables. Group comparisons used $\chi^{2}$ test for qualitative variables, and Wilcoxon rank-sum test for quantitative variables, respectively. Multiple linear regression models were used to assess the independent association between eGFR and haematological indices, while adjusting for age and gender.

\section{RESULTS}

\section{Participant characteristics}

The initial study sample comprised 1647 participants. Of those, 83 were excluded due to missing data on serum creatinine or any of the variables required to estimate kidney function, including age and gender. The general characteristics and the haematological profile of the study population are summarised in tables 1 and 2, respectively. The final sample included 1564 participants, of which $24.9 \%$ were male, with a group median age of 50 years. The crude prevalence of CKD was $6 \%$ and $3 \%$, based on the MDRD and CKD-EPI equations, respectively. Of those participants with MDRD-diagnosed CKD, 80.7\%, 14.8\% and $4.5 \%$ where in stages 3,4 and 5 , respectively. Similarly, of those diagnosed by means of the CKD-EPI equation, $68.9 \%, 24.4 \%$ and $6.7 \%$ where in stages 3,4 and 5 , respectively. MDRD-diagnosed CKD participants had higher creatinine levels (111.5 vs $59 \mathrm{\mu mol} / \mathrm{L} ; \mathrm{p}<0.0001)$ and lower eGFR ( 48.2 vs $\left.104 \mathrm{~mL} / \mathrm{min} / 1.73 \mathrm{~m}^{2} ; \mathrm{p}<0.0001\right)$, were on average older (68 vs 49 years; $\mathrm{p}<0.0001$ ), with a higher WC $(97.7$ vs $91.2 \mathrm{~cm} ; \mathrm{p}=0.0001)$, BMI (30.3 vs $28.3 \mathrm{~kg} /$ $\mathrm{m}^{2} ; \mathrm{p}=0.0096$ ), and SBP (142 vs $\left.125 \mathrm{~mm} \mathrm{Hg} ; \mathrm{p}<0.0001\right)$, compared with participants with normal kidney function. Furthermore, MDRD-diagnosed CKD participants had higher fasting and 2-hour blood glucose (5.3 vs $5.0 \mathrm{mmol} / \mathrm{L} ; \mathrm{p}<0.0001$ and 7.2 vs $6.0 \mathrm{mmol} / \mathrm{L} ; \mathrm{p}<0.0001$, respectively), HbAlc levels (6.2 vs 5.7\%; p<0.0001), fasting and 2-hour insulin levels $(8.4$ vs $6.7 \mathrm{IU} / \mathrm{L}$; $\mathrm{p}=0.0089$ and 62.0 vs $37.5 \mathrm{IU} / \mathrm{L} ; \mathrm{p}=0.0002$, respectively), higher HOMA-IR index (2.1 vs 1.6; $\mathrm{p}=0.0004)$, hsCRP ( 4.7 vs $4.0 \mu \mathrm{g} / \mathrm{mL} ; \mathrm{p}=0.0492)$, TG $(1.6$ vs $1.2 \mathrm{mmol} / \mathrm{L}$; $\mathrm{p}<0.0001)$ and TC (5.4 vs $5.1 \mathrm{mmol} / \mathrm{L} ; \mathrm{p}=0.024)$; with similar LDL-C (3.2 vs $3.1 \mathrm{mmol} / \mathrm{L} ; \mathrm{p}=0.0668)$ and HDL-C levels ( 1.3 vs $1.3 \mathrm{mmol} / \mathrm{L} ; \mathrm{p}=0.7106)$ compared with those without CKD. When subdividing the groups based on CKD diagnosed by the CKD-EPI equation, similar differences were observed, with the exception of BMI, hsCRP and TC which showed no difference between the groups (28.3 vs $28.4 \mathrm{~kg} / \mathrm{m}^{2}$; $\mathrm{p}=0.384$, 4.8 vs $4.0 \mu \mathrm{g} / \mathrm{mL} ; \mathrm{p}=0.4268$, 5.3 vs $5.1 \mathrm{mmol} / \mathrm{L} ; \mathrm{p}=0.2226$, respectively). Participants with reduced kidney function, both MDRD and CKD-EPI diagnosed, had a similar prevalence of overweight and obesity, however had a higher prevalence of hypertension and T2D, despite similar prevalence of pre-diabetes (IFG and IGT) between the two groups.

The RBC indices, including RBC count, haematocrit and haemoglobin levels were consistently lower in CKD participants compared with the group with normal kidney function (all $p<0.0001$ ), irrespective of the eGFR equation 


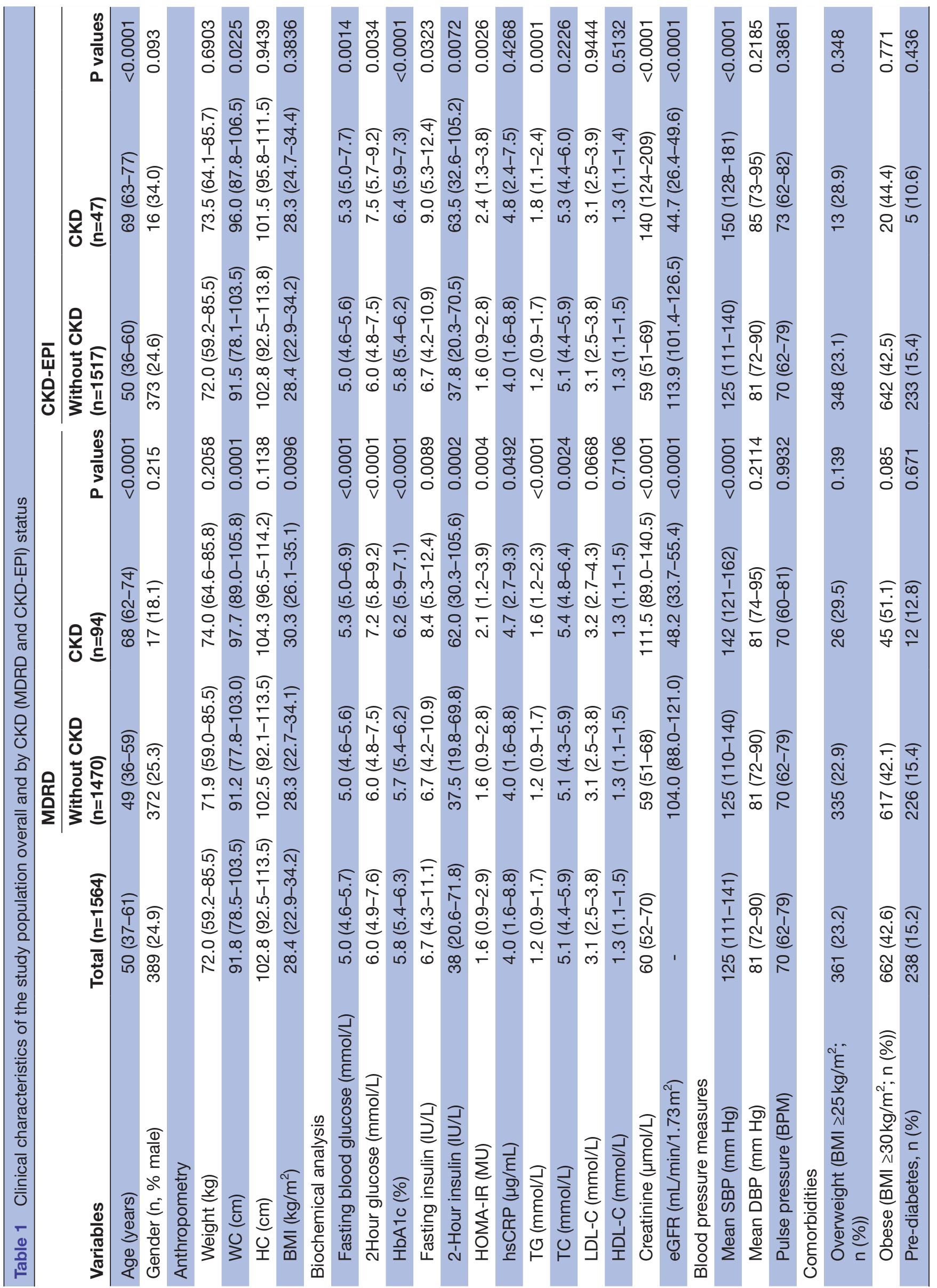




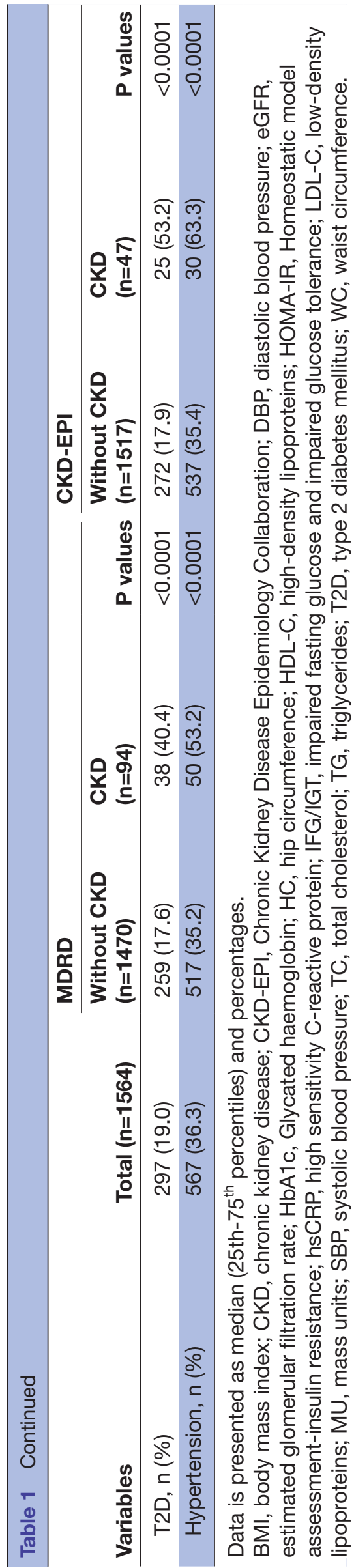

used. Conversely, the morphology of the RBCs were not different, as similar values for MCV, MCH, MCHC and RDW were observed between CKD participants and the participants with normal kidney function. Despite not showing any significant difference in total WBC count between the two groups, the number of lymphocytes were lower and neutrophil count and the ratio of lymphocytes to neutrophil higher in the CKD group compared with those individuals with normal kidney function; with the remaining $\mathrm{WBC}$ indices similar in the two groups. The platelet count was similar in both groups. Furthermore, based on the K/DOQI guidelines, 45.5\% (MDRD) and $57.8 \%$ (CKD-EPI) of the CKD participants had anaemia, with the majority of cases being normocytic. Moreover, the prevalence of anaemia increased with increasing severity of CKD, from $37.2 \%$ at stage $3 \%$ to $82.4 \%$ at stage $4-5$.

Association between the different haematological indices and eGFR

The age and gender-adjusted associations between the different haematological indices and eGFR, estimated by means of the MDRD and CKD-EPI equations, are presented in table 3. Based on the CKD-EPI, however not the MDRD equation, eGFR was positively associated with all the RBC indices, including total RBC count, haemoglobin and haematocrit levels. eGFR was not associated with total WBC count, however a lower lymphocyte count was associated with a lower eGFR, and N/L ratio was inversely associated with eGFR. Furthermore, male gender was significantly associated with all haematological measures, except basophil count and eosinophil count, and age was inversely associated with all RBC indices, lymphocytes, neutrophils, platelet count, MCHC and positively associated with RDW.

\section{DISCUSSION}

In this community-based sample of mixed-ancestry South Africans, we have shown that the haematological profile of individuals with reduced eGFR $\left(<60 \mathrm{~mL} / \mathrm{min} / 1.73 \mathrm{~m}^{2}\right)$ are substantially impaired compared with those with normal kidney function, giving rise to the high prevalence of anaemia in this screen-detected CKD population. Furthermore, despite eGFR being positively associated with RBC indices, indicative of the severity of kidney function impairment, the disease state had no effect on the morphology of the RBC. Lastly, we confirmed that a chronic proinflammatory state exists in participants with CKD.

This study, which is in accordance with other studies in Africa and other low-income and middle-income countries ${ }^{36-42}$ has shown that CKD is associated with significant impairment in RBC indices. Indeed, we have shown that total RBC count, haemoglobin concentration and percentage haematocrit were substantially reduced in participants with eGFR below $60 \mathrm{~mL} / \mathrm{min} / 1.73 \mathrm{~m}^{2}$, compared with those with normal kidney function, 


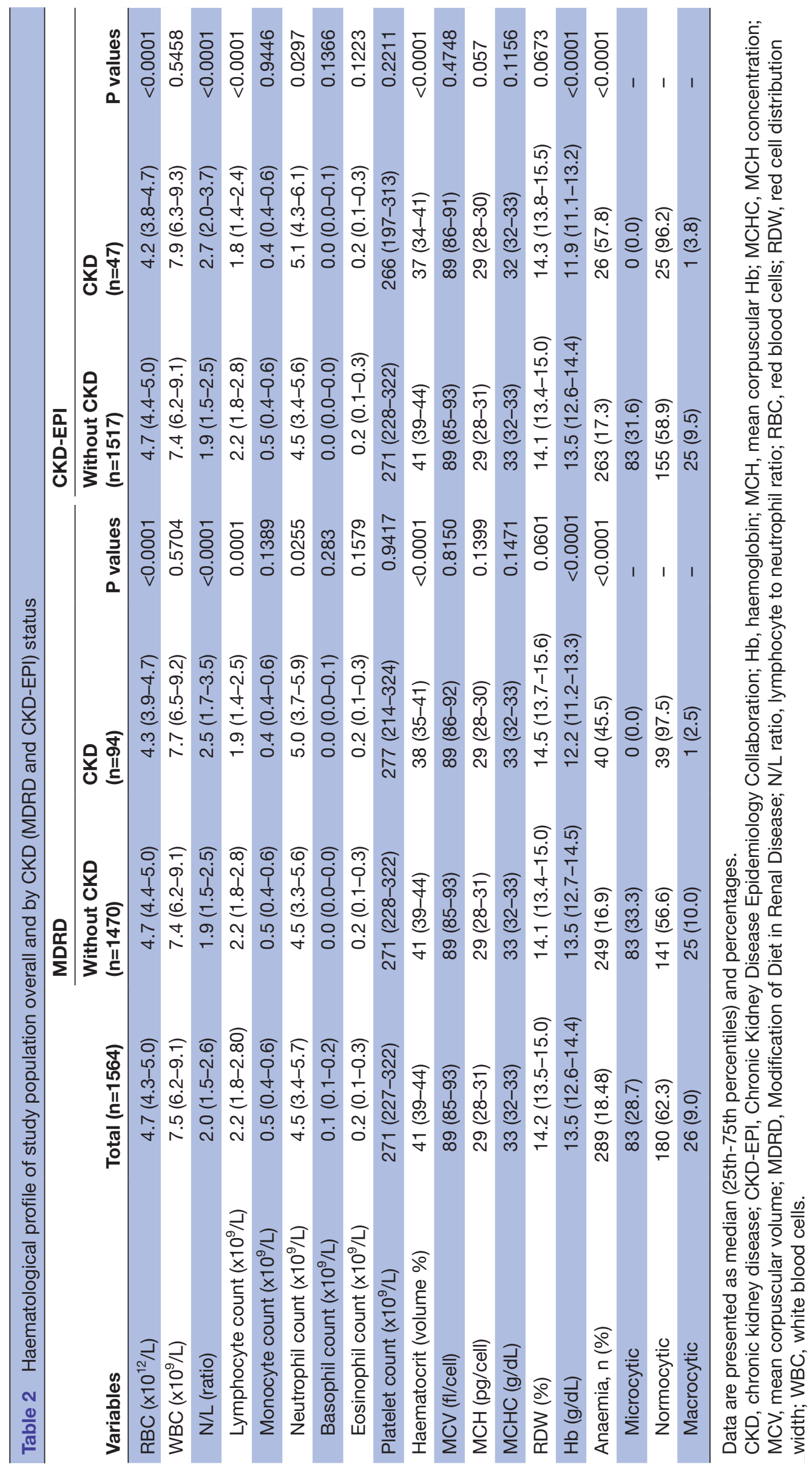




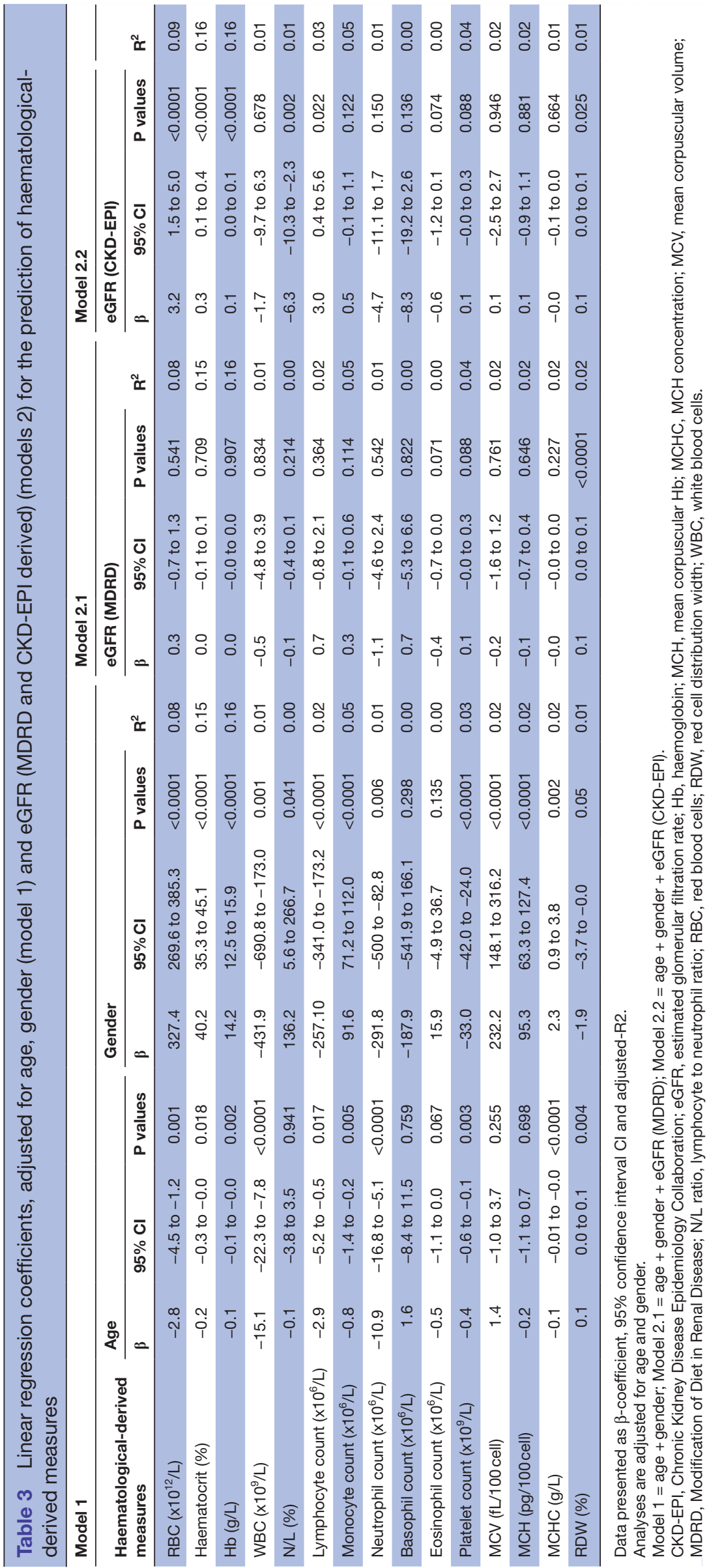


independent of age and gender. Since erythropoietin is produced mainly by the proximal tubule of the nephron, kidney function decline will result in a decline in erythropoietin production and as a consequence result in decreased haemoglobin synthesis, leading to a fall in total RBC count. ${ }^{17}$ This significant reduction in $\mathrm{RBC}$, inevitably gives rise to anaemia. ${ }^{14}$ Indeed, our study and numerous other studies have shown that the severity of anaemia increases with disease progression; with most of these studies showing anaemia at least twice as prevalent in participants with CKD, compared with the general adult population. ${ }^{37}$ Furthermore, we found that $17 \%$ of the sample population with normal kidney function had haemoglobin levels $<13.5 \mathrm{~g} / \mathrm{dL}$ and $<12 \mathrm{~g} / \mathrm{dL}$ for men and women, respectively. However, this is not uncommon in Africa as previous studies have found that Africa has a high prevalence of anaemia caused by iron deficiency. In South Africa in particular, the South African National Health and Nutrition Examination Survey ${ }^{43}$ showed that $22 \%$ and $12.2 \%$ of adult females and males have anaemia.

The activation of the immune system, caused by inflammation, increases WBC counts ${ }^{23}$; emphasising the potential of WBC indices as a surrogate marker of inflammation in CKD. ${ }^{20}$ Our study showed that despite no correlation between total WBC and reduced kidney function, CKD was associated with higher neutrophil and lower lymphocyte counts; both of which are independently associated with the promotion of atherosclerosis ${ }^{445}$ and poor cardiovascular outcomes. ${ }^{46} \mathrm{~N} / \mathrm{L}$ ratio, which combines the predictive power of both increased neutrophil count and decreased lymphocyte count, ${ }^{47}$ was associated with reduced eGFR in our study, as also found in other studies. ${ }^{2348} 49$ Indeed previous studies, which included patients with CKD on haemodialysis ${ }^{2348}$ and predialysis, ${ }^{49}$ showed that an increased $\mathrm{N} / \mathrm{L}$ ratio was associated with known inflammatory markers such as tumour necrosis factor- $\alpha,{ }^{23}$ interleukin 6 and hsCRP levels. ${ }^{49}$ These studies demonstrated that these well-established markers of inflammation were independent factors for predicting $\mathrm{N} / \mathrm{L}$ ratio, thus presenting $\mathrm{N} / \mathrm{L}$ ratio as an inflammatory biomarker for patients with CKD. Since full blood count analysis are done routinely, and a relatively affordable and easy measure to acquire, these findings are especially valuable taking into account the severely resource limited setting found in Africa and other low-income and middle-income countries.

Our study has a few limitations. This study was conducted in only one geographical area which may not adequately reflect all the mixed ancestry population groups in Sub-Saharan Africa. Furthermore, this was a community-based sample with high female to male participation, however the latter being a common trend in South African population studies. Our study also used a single serum creatinine measure to determine the grade of kidney function and did not include estimates of albuminuria. Albuminuria, in particular, is required for clinical and aetiological diagnosis of CKD, as this information is important particularly in the interpretation of eGFR greater that $60 \mathrm{~mL} / \mathrm{min} / 1.73 \mathrm{~m}^{2}$ where inaccuracies of the eGFR equations are greatest. It is however a common practice in community-based studies to diagnose CKD using a single measurement of serum creatinine. Furthermore, we did not investigate other haematinic deficiencies, such as vitamin $\mathrm{B}_{12}$ and iron deficiencies which, if present however, are less likely to affect haematological profile in a differential way in people with and without CKD. However, despite these limitations, we are not aware of other studies that have assessed the haematological profile of individuals with reduced kidney function in a population-based setting in Africa, even more specific, individuals of mixed-ancestry. Furthermore, we studied a community with a high burden of obesity, hypertension and diabetes, reflective of the current burden in Africa. This study provides much needed evidence for the association between the haematological profile and CKD as population-based data on the haematological profile of people with CKD in Africa are very limited.

In conclusion, the findings from our study are valuable as full blood count analyses are done routinely and are relatively affordable, taking into account the severely resource-limited setting found in Africa and other low-income and middle-income countries. Furthermore, though it still remains unclear whether the advocated kidney function estimators provide accurate estimates of CKD burden in African populations, ${ }^{49}$ the correlation of these estimates, with deteriorating profile of blood cell counts, suggests that these advocated GFR estimates, particularly the CKD-EPI equation, to some extent, measure kidney function in African populations.

\section{Author affiliations}

${ }^{1}$ Non-Communicable Diseases Research Unit, South African Medical Research Council, Cape Town, South Africa

${ }^{2}$ Department of Biomedical Sciences, Faculty of Health and Wellness Science, Cape Peninsula University of Technology, Cape Town, South Africa

${ }^{3}$ Division of Chemical Pathology, Faculty of Medicine and Health Sciences, University of Stellenbosch, Cape Town, South Africa

${ }^{4}$ Department of Medicine, University of Cape Town, Cape Town, South Africa

Acknowledgements We are grateful to the Cape Town VMH study investigation team and population of Bellville-South for their participation.

Contributors Study conception and funding acquisition: TEM, APK, RTE. Operationalisation and supervision of the data collection: TEM. Data analysis and interpretation: CG, APK. Drafting the manuscript: CG, APK. Critical revision of the manuscript and approval of the final version: all coauthors.

Funding The South African Medical Research Council (SAMRC) funded this research project with funds from National Treasury under its Economic Competitiveness and Support Package (MRC-RFA-UFSP-01-2013/NMH Study).

Competing interests None declared.

Patient consent Not required.

Ethics approval The study was approved by the Research Ethics Committees of the Cape Peninsula University of Technology and Stellenbosch University (NHREC: REC-230 408-014 and N14/01/003, respectively). The study was conducted in accordance with the Declaration of Helsinki. Permission to conduct the study was also obtained from relevant authorities including the city and community authorities.

Provenance and peer review Not commissioned; externally peer reviewed.

Data sharing statement The datasets used and/or analysed during the current study are available from the corresponding author on reasonable request. 
Open access This is an open access article distributed in accordance with the Creative Commons Attribution Non Commercial (CC BY-NC 4.0) license, which permits others to distribute, remix, adapt, build upon this work non-commercially, and license their derivative works on different terms, provided the original work is properly cited, appropriate credit is given, any changes made indicated, and the use is non-commercial. See: http://creativecommons.org/licenses/by-nc/4.0/.

\section{REFERENCES}

1. Bolton $\mathrm{K}$, Culleton $\mathrm{B}$, Harvey K. K/DOQI clinical practice guidelines for chronic kidney disease: evaluation, classification, and stratification. Kidney Disease Outcome Quality Initiative. Am JKidney Dis 2002;39:S1-246.

2. Nitta K, Okada K, Yanai M, et al. Aging and chronic kidney disease. Kidney Blood Press Res 2013;38:109-20.

3. Lozano R, Naghavi M, Foreman K, et al. Global and regional mortality from 235 causes of death for 20 age groups in 1990 and 2010: a systematic analysis for the Global Burden of Disease Study 2010. Lancet 2012;380:2095-128.

4. Eckardt KU, Coresh J, Devuyst O, et al. Evolving importance of kidney disease: from subspecialty to global health burden. Lancet 2013;382:158-69.

5. Ayodele OE, Alebiosu CO. Burden of chronic kidney disease: an international perspective. Adv Chronic Kidney Dis 2010;17:215-24.

6. Naicker S. End-stage renal disease in sub-Saharan Africa. Ethn Dis 2009;19:S1-13-5.

7. Peralta CA, Risch N, Lin F, et al. The Association of african ancestry and elevated creatinine in the Coronary Artery Risk Development in Young Adults (CARDIA) Study. Am J Nephrol 2010;31:202-8.

8. Kiberd BA, Clase CM. Cumulative risk for developing end-stage rena disease in the US population. J Am Soc Nephrol 2002;13:1635-44.

9. Stanifer JW, Jing B, Tolan S, et al. The epidemiology of chronic kidney disease in sub-Saharan Africa: a systematic review and metaanalysis. Lancet Glob Health 2014;2:e174-e181.

10. Stanifer JW, Muiru A, Jafar TH, et al. Chronic kidney disease in low- and middle-income countries. Nephrol Dial Transplant 2016;31:868-74.

11. Hamer RA, El Nahas AM. The burden of chronic kidney disease. BMJ 2006;332:563-4.

12. Jha V, Garcia-Garcia G, Iseki K, et al. Chronic kidney disease: global dimension and perspectives. Lancet 2013;382:260-72.

13. Babitt JL, Lin HY. Mechanisms of anemia in CKD. J Am Soc Nephrol 2012;23:1631-4.

14. Astor BC, Muntner $P$, Levin A, et al. Association of kidney function with anemia: the third national health and nutrition examination survey (1988-1994). Arch Intern Med 2002;162:1401-8.

15. Webster AC, Nagler EV, Morton RL, et al. Chronic kidney disease. Lancet 2017;389:1238-52.

16. Kazmi WH, Kausz AT, Khan S, et al. Anemia: an early complication of chronic renal insufficiency. Am J Kidney Dis 2001;38:803-12.

17. Kutuby F, Wang S, Desai C, et al. Anemia of chronic kidney disease. Dis Mon 2015;61:421-4

18. Levey AS, Coresh J. Chronic kidney disease. The Lancet 2012;379:165-80.

19. Stenvinkel $P$, Heimbürger $O$, Paultre $F$, et al. Strong association between malnutrition, inflammation, and atherosclerosis in chronic renal failure. Kidney Int 1999;55:1899-911.

20. Okyay GU, Inal S, Oneç K, et al. Neutrophil to lymphocyte ratio in evaluation of inflammation in patients with chronic kidney disease. Ren Fail 2013;35:29-36.

21. Azab B, Zaher M, Weiserbs KF, et al. Usefulness of neutrophil to lymphocyte ratio in predicting short- and long-term mortality after non-ST-elevation myocardial infarction. Am J Cardiol 2010;106:470-6.

22. Uthamalingam S, Patvardhan EA, Subramanian S, et al. Utility of the neutrophil to lymphocyte ratio in predicting long-term outcomes in acute decompensated heart failure. Am J Cardiol 2011;107:433-8.

23. Turkmen K, Guney I, Yerlikaya FH, et al. The relationship between neutrophil-to-lymphocyte ratio and inflammation in end-stage renal disease patients. Ren Fail 2012;34:155-9.

24. Masconi K, Matsha TE, Erasmus RT, et al. Independent external validation and comparison of prevalent diabetes risk prediction models in a mixed-ancestry population of South Africa. Diabetol Metab Syndr 2015;7:42.

25. Kengne AP, Erasmus RT, Levitt NS, et al. Alternative indices of glucose homeostasis as biochemical diagnostic tests for abnormal glucose tolerance in an African setting. Prim Care Diabetes 2017;11:119-31.

26. Chalmers J, MacMahon S, Mancia G, et al. 1999 World health organization-international society of hypertension guidelines for the management of hypertension. Guidelines sub-committee of the world health organization. Clin Exp Hypertens 1999;21:1009-60.

27. Alberti KG, Zimmet PZ. Definition, diagnosis and classification of diabetes mellitus and its complications. Part 1: diagnosis and classification of diabetes mellitus provisional report of a WHO consultation. Diabet Med 1998;15:539-53.

28. Friedewald WT, Levy RI, Fredrickson DS. Estimation of the concentration of low-density lipoprotein cholesterol in plasma, without use of the preparative ultracentrifuge. Clin Chem 1972;18:499-502.

29. Levey AS, Bosch JP, Lewis JB, et al. A more accurate method to estimate glomerular filtration rate from serum creatinine: a new prediction equation. Modification of diet in renal disease study group. Ann Intern Med 1999;130:461-70.

30. Levey AS, Stevens LA, Schmid CH, et al. A new equation to estimate glomerular filtration rate. Ann Intern Med 2009;150:604-12.

31. Levey AS, Coresh J, Balk E, et al. National Kidney Foundation practice guidelines for chronic kidney disease: evaluation, classification, and stratification. Ann Intern Med 2003;139:137-47.

32. KDOQINational Kidney Foundation. KDOQI clinical practice guidelines and clinical practice recommendations for anemia in chronic kidney disease. Am J Kidney Dis 2006;47:S11-145.

33. Bessman JD, Johnson RK. Erythrocyte volume distribution in normal and abnormal subjects. Blood 1975;46:369-79.

34. World Health Organization. A global brief on Hypertension: Silent killer. global public health crisis 2013

35. World Health Organisation, International Diabetes Federation. Definition and diagnosis of diabetes and intermediate hyperglycemia. Consultation WI. Geneva: World Health Organisation, International Diabetes Federation, 2006.

36. Afshar R, Sanavi S, Salimi J, et al. Hematological profile of chronic kidney disease (CKD) patients in Iran, in pre-dialysis stages and after initiation of hemodialysis. Saudi J Kidney Dis Transp/ 2010;21:368-71

37. Akinsola A, Durosinmi MO, Akinola NO. The haematological profile of Nigerians with chronic renal failure. Afr J Med Med Sci 2000;29:13-16.

38. Asif N, Hasan S, Hassan K. Hematological changes in patients of chronic renal disease and their response to treatment with erythropoietin. Int J Pathol 2015;13:14-19.

39. Bhattacharjee K, Das D, Rabha P, et al. A Study on hematologica profile in patients of chronic renal failure with special reference to serum iron profile. Journal of Evidence Based Medicine and Healthcare 2015;2:8212-9.

40. Dabrowska MM, Mikula T, Wiercinska-Drapalo A. The anemia prevalence and the association between complete blood count analysis and renal function parameters in HIV-1-infected patients. Curr HIV Res 2012;10:247-51

41. Islam MN, Ferdous A, Zahid AZ, et al. Haematological profile of patients with chronic kidney disease in Northern Bangladesh. Dinajpur Med Col J 2015;8:21-7.

42. Latiweshob OB, Elwerfaly $\mathrm{HH}$, Sheriff DS, et al. Haematological changes in predialyzed and hemodialyzed chronic kidney disease patients in libya. IOSR J of Dental and Med Sciences 2017;16:106-12

43. Shisana O, Labadarios D, Rehle T, et al. The South African National Health and Nutrition Examination Survey (SANHANES-1). 2013.

44. Drechsler M, Döring Y, Megens RT, et al. Neutrophilic granulocytes - promiscuous accelerators of atherosclerosis. Thromb Haemost 2011;106:839-48.

45. Núñez J, Miñana G, Bodí V, et al. Low lymphocyte count and cardiovascular diseases. Curr Med Chem 2011;18:3226-33.

46. Reddan DN, Klassen PS, Szczech LA, et al. White blood cells as a novel mortality predictor in haemodialysis patients. Nephrol Dial Transplant 2003;18:1167-73.

47. Solak Y, Yilmaz MI, Sonmez A, et al. Neutrophil to lymphocyte ratio independently predicts cardiovascular events in patients with chronic kidney disease. Clin Exp Nephrol 2013;17:532-40.

48. An X, Mao HP, Wei X, et al. Elevated neutrophil to lymphocyte ratio predicts overall and cardiovascular mortality in maintenance peritoneal dialysis patients. Int Urol Nephrol 2012;44:1521-8.

49. Agoons DD, Balti EV, Kaze FF, et al. Performance of three glomerular filtration rate estimation equations in a population of sub-Saharan Africans with Type 2 diabetes. Diabet Med 2016;33:1291-8. 